\title{
La libertad religiosa en los orígenes del Derecho eclesiástico italiano: Francesco Ruffini (1863-1934)
}

\section{Religious Freedom in the Origins of Italian Ecclesiastical Law: Francesco Ruffini (1863-1934)}

\section{Pilar SOLÁ GRANELL}

\section{Profesora Contratada Doctora}

Universidad Católica de Valencia San Vicente Mártir. Facultad de Derecho Canónico pilar.sola@ucv.es

Resumen: Francesco Ruffini, fundador del Derecho eclesiástico italiano junto a Francesco Scaduto, defiende la centralidad de la libertad religiosa de los ciudadanos como objeto de las normas estatales en materia eclesiástica. Su propuesta es un referente en la construcción dogmática de esta libertad en el ámbito del Derecho europeo. Al estudiar las principales tesis de su magisterio se descubren muchos aspectos coincidentes con la propuesta de libertad religiosa que, unos años más tarde, sostendrá la Declaración conciliar Dignitatis humanae.

Palabras clave: Libertad religiosa, Derecho eclesiástico italiano, Dignitatis humanae.
Abstract: Francesco Ruffini, founder of Italian ecclesiastical law with Francesco Scaduto, defends the centrality of religious freedom of citizens as an object of state laws in ecclesiastical matters. His proposal is a benchmark in the dogmatic construction of this freedom in the European law. By studying the main theses of his teaching, we can found coincident aspects about religious freedom that the Conciliar Declaration Dignitatis humanae will teach a few years later.

Keywords: Religious Freedom, Italian Ecclesiastical Law, Dignitatis humanae. 


\section{INTRODUCCIÓN}

- 1 Derecho eclesiástico se configura como disciplina universitaria en Italia a finales del siglo XIX, de la mano de Francesco Scaduto (1858-1942) y Francesco Ruffini (1863-1934). Scaduto propicia un enfoque institucional de la materia al centrarla en el estudio de las relaciones Iglesia-Estado, mientras que Ruffini defiende que la principal función de las normas estatales en materia eclesiástica debe ser la tutela y garantía de la libertad religiosa de los ciudadanos. Esta intuición jurídica hace de él un autor de especial consideración en el estudio de la evolución de esta libertad en el ámbito del Derecho europeo. Dar a conocer su concepto de la libertad religiosa es el objeto de este trabajo, teniendo en cuenta que sus enseñanzas vaticinan algunos aspectos que, treinta años más tarde, se encontrarán también en el documento conciliar Dignitatis bumanae.

\section{El nacimiento del Derecho eclesiástico en Italia}

El Derecho eclesiástico nace en Alemania y llega a Italia a través de Francesco Ruffini, que en 1893 publica la traducción italiana del Tratado de Derecho eclesiástico católico y evangélico de Emil Friedberg ${ }^{1}$. Esta publicación permite dar a conocer los estudios alemanes sobre el Kirchenrecht, y son tomados como paradigma para el desarrollo del Derecho eclesiástico italiano ${ }^{2}$.

${ }^{1}$ Francesco Ruffini nace el 10-IV-1863 en Lessolo Canavese (Turín). Historiador del Derecho, jurista, canonista y político. Inicia la docencia universitaria en el curso 1892-1893 en Pavía; al año siguiente obtiene la cátedra de Derecho eclesiástico en Génova. A partir de 1899 comienza a enseñar Historia del Derecho italiano en Turín, y en 1908 obtiene la cátedra de Derecho eclesiástico en esta misma universidad. Gran parte de su formación intelectual se forja en Alemania, principalmente debido a su amistad con Emil Friedberg, una de las mayores figuras del momento en el ámbito del Derecho canónico y eclesiástico. En 1914 participa activamente en la vida política del país, desde las filas liberales. Su formación liberal le lleva a oponerse a la firma de los Pactos de Letrán y a rechazar, en 1931, el juramento de fidelidad al régimen fascista. Por este motivo se vio obligado a abandonar la docencia universitaria. Muere en Turín el 29-III-1934. Cfr. A. BERTOLA, «Ruffini, F.», Enciclopedia Cattolica, Firenze 1952, 1434; A. ColOMBo, «Ruffini, F.», en AA. Vv. - P. FEDELE, Grande Dizionario Enciclopedico UTET, Torino ${ }^{4} 1990$, XVII, 873; A. C. JEMOLO, «Ruffini, F.», en A. AZARA - E. EUla (dirs.), Novissimo Digesto Italiano, XVI, Torino 1982, 277.

2 Cfr. A. DE la Hera, La ciencia del Derecho eclesiástico en Italia. Notas para su recepción en España, El fenómeno religioso en España, Instituto de Estudios políticos, Madrid 1972, 77-80. Para precisar el concepto Derecho eclesiástico alemán, explica A. de Fuenmayor: «A raíz de la Reforma, los cristianos separados introducen en la ciencia alemana una nueva terminología: conservan el término Derecho canónico, pero reservan esta expresión para referirse al Derecho anterior a la Reforma que se contiene en el Corpus Iuris Canonici; y denominan Derecho eclesiástico (Kirchenrecht) 
La disciplina se consolida en la universidad italiana a finales del siglo XIX bajo el magisterio de Ruffini y Scaduto, si bien ambos profesores mantienen desde el principio posturas distintas acerca de cuál sea el objeto del Derecho eclesiástico. Hay que tener en cuenta que esta diversidad de enfoques viene propiciada, en gran parte, por las circunstancias históricas del momento que desembocaron en un duro enfrentamiento entre la Iglesia y el Estado. El Estado piamontés, principal artífice del proceso unificador, había desplegado desde 1848 una actividad legislativa en sentido laicista invocando los principios de la doctrina liberal. Con ocasión de la constitución del Parlamento italiano en 1861, esta legislación liberal del Piamonte se extiende a todo el reino de Italia, suprimiéndose los Acuerdos estipulados entre la Santa Sede y los Estados preunitarios. El Código Civil de 1865 seculariza los principios y fundamentos del Derecho de familia, mientras que en 1866 dos leyes retiran el reconocimiento de las congregaciones, corporaciones y órdenes religiosas ${ }^{3}$. Cuando en 1870 las tropas nacionales toman la ciudad de Roma y despojan a la Santa Sede de los últimos restos de su soberanía temporal, se produce una confrontación inevitable entre el nuevo Reino de Italia y el Romano Pontífice, señor temporal del Estado de la Iglesia: como reacción ante el asalto estatal, Pío IX se declara prisionero del Estado italiano ${ }^{4}$. Tras la ocupación de Roma, en 1871 el Parlamento italiano impone unilateralmente la Ley de Garantías a la Santa Sede para resolver la cuestión romana, provocando un nue-

\footnotetext{
al Derecho posterior relativo a materias eclesiásticas. Este Derecho eclesiástico está constituido por normas emanadas del Estado y de las distintas iglesias (es la época de las iglesias nacionales). (...) El principal rasgo del criterio protestante estriba en calificar a un Derecho como eclesiástico no por razón de su fuente de origen, es decir, las iglesias, sino por razón de su objeto o materia (las materias eclesiásticas)»: cfr. A. DE FuENMAYOR, Derecho eclesiástico del Estado Español, Comares, Granada 2007, 5.

3 Cfr. S. LaricCiA, «Stato e Chiesa (rapporti tra)», en Aa. Vv. - F. CALASSo, Enciclopedia del Diritto, XLIII, Giuffrè, Milano 1990, 892-893. Una exposición detallada de la actividad legislativa del Piamonte en este periodo se puede consultar en: cfr. V. Tozzí, 150 anni di unità dell'Italia. Breve storia e problema attualli della libertà religiosa, Anuario de Derecho eclesiástico del Estado 28 (2012) 679-680.

${ }^{4}$ Defender la existencia de los Estados Pontificios no era sólo una cuestión de carácter temporal, sino garantía del ejercicio de la libertad de la Iglesia necesaria para desarrollar su misión espiritual en el mundo. La jerarquía eclesiástica reclamaba estas posesiones, fundamentalmente, en atención a un título de carácter sobrenatural: cfr. Pío IX, Enc. Ubi nos, 7: «Nos vemos obligados a confirmar una vez más (...) que el principado civil de la Santa Sede fue por singular decreto de la Divina Providencia dado al Romano Pontífice y que el mismo es necesario para que el Romano Pontífice, no sujeto jamás a ningún príncipe o potestad civil, pueda ejercer con plenísima libertad por la Universal Iglesia Católica la potestad y autoridad divinamente recibida del mismo Cristo Señor nuestro y mirar por el mayor bien, utilidad y necesidades de la misma Iglesia».
} 
vo enfrentamiento entre la Iglesia y el Estado ${ }^{5}$. No es de extrañar, por tanto, el juicio negativo de la jerarquía eclesiástica ante la actividad del nuevo Estado unificado. La Iglesia no deja de denunciar los abusos estatales que cercenan su libertad sagrada: de hecho, la Sagrada Penitenciaría decreta el non expedit que prohíbe a los católicos italianos la participación en la vida política del país ${ }^{6}$.

Esta confrontación marca decisivamente la configuración del Derecho eclesiástico italiano, pues lleva a centrar la atención en las instituciones y no en los individuos. Además también el positivismo jurídico y el liberalismo estatal propios del XIX son importantes en la formación de la disciplina, al confirmar la superioridad del ordenamiento estatal como fuente normativa respecto a los ordenamientos confesionales. Por todo ello Scaduto propone que los cursos de Derecho eclesiástico se ocupen, fundamentalmente, del estudio de las relaciones entre la Iglesia y el Estado, potenciando un enfoque institucional de la materia ${ }^{7}$. Ésta es la orientación seguida por los eclesiasticistas italianos de la primera hora: como observa Lombardía, los esquemas de los más importantes manuales de Derecho eclesiástico publicados entre 1892 y 1927 (Scaduto, Olmo, Calisse, Galente, Schiappoli, Jemolo) son muestra de ello ${ }^{8}$.

Frente a esta corriente institucional mayoritaria Ruffini proclama la necesidad de un cambio de enfoque, situando como centro de la disciplina no tanto las relaciones entre la Iglesia y el Estado sino el derecho de libertad

\footnotetext{
${ }^{5}$ Pío IX, Enc. Ubi nos, 4: «Con todo juzgamos ser obligación de Nuestro oficio apostólico declararos solemnemente a vosotros y a todo el Orbe que no sólo las llamadas cauciones y que vanamente han sido impuestas por el gobierno subalpino, sino cualquier clase de títulos, honores, inmunidades y privilegios y cuanto sobrevenga con el nombre de cauciones o garantías, de ninguna manera pueden servir para asegurar el expedito y libre uso de la potestad a Nosotros divinamente confiada y para proteger la necesaria libertad de la Iglesia».

${ }^{6}$ Cfr. G. Redondo, La Iglesia en el mundo contemporáneo, Eunsa, Pamplona 1979, II, 38: «Ya en 1857 Don Margotti había formulado el conocido nè eletti, nè elettori. En 1868 Pío IX hacía suya la idea y, aunque sólo como consejo, lanzaba, mediante un decreto de la Sagrada Penitenciaría la doctrina del non expedit: los católicos italianos debían abstenerse de participar, en cualquier forma, en la construcción, administración y dirección política del nuevo Estado liberal unificado».

${ }^{7}$ Acerca del uso que Scaduto hace del término Derecho eclesiástico, cfr. I. C. IBáN, En los orígenes del Derecho eclesiástico, Boletín Oficial del Estado, Madrid 2004, 145-163.

${ }^{8}$ Cfr. P. Lombardía, Derecho eclesiástico del Estado español, Eunsa, Pamplona 1980, 141: «Los cursos de Derecho eclesiástico (italiano) se ocupaban preferentemente de la relevancia de la disciplina canónica en el ordenamiento del Estado y de las rectificaciones que el Estado hacía, mediante el ejercicio de su potestad legislativa, en la disciplina canónica de la organización eclesiástica. De aquí un enfoque preferentemente institucional». Cfr. también: S. FERRARI, Ideologia e dogmatica nel diritto ecclesiastico italiano. Manuali e riviste (1929-1979), Giuffrè, Milano 1979, 127-128.
} 
religiosa ${ }^{9}$. Lidera así la propuesta del Derecho eclesiástico como ciencia jurídica centrada en la legislatio libertatis. Si bien su propuesta no fue acogida en un principio, ésta dará fruto años más tarde una vez superado el régimen totalitario fascista, régimen que también acentúa el enfoque institucional de las enseñanzas de los eclesiasticistas italianos. Será con la Constitución de 1948 cuando el deseado cambio de orientación del Derecho eclesiástico planteado por Ruffini empiece a arraigar en Italia ${ }^{10}$.

Más allá de la polémica doctrinal que suscita el objeto del Derecho eclesiástico ${ }^{11}$, no hay duda de que Francesco Ruffini es uno de los juristas que con más ahínco defiende la centralidad de la libertad religiosa en el ámbito de la ciencia jurídica europea del momento. En este sentido baste recordar que será el único de los eclesiasticistas italianos que dedique dos obras íntegras a este tema: La libertà religiosa. Storia dell'idea (Torino 1901) y Corso di Diritto ecclesiastico italiano. La libertà religiosa come diritto pubblico subiettivo (Torino 1924). De aquí el interés por conocer las tesis de este autor sobre de esta libertad.

\section{LA Libertad RELigiosa EN LA ObRa de Francesco RufFini}

Para comprender el planteamiento de Ruffini es necesario subrayar previamente la decisiva influencia que la Escuela Histórica alemana ejerce en su formación jurídica y en su método de estudio. De esta Escuela aprende a plantear y resolver los problemas humanos y jurídicos desde una perspectiva histórica, convencido de que los datos de la historia son los que permiten construir un sistema adecuado a las exigencias de la justicia. El método histórico, funda-

\footnotetext{
${ }^{9}$ Cfr. F. RuFfinI, Corso di Diritto ecclesiastico italiano. La libertà religiosa come diritto pubblico subiettivo, F. Bocca, Torino 1924, X-XI: «La disciplina va secondo noi riguardata ormai, non tanto dal punto di vista dei rapporti fra coteste due entitá, di per sé e quasi astrattamente considerate, quanto da quello del diritto del cittadino ad un assetto di tali rapporti che rispetti e garantisce, innanzitutto, la sua libertá di fede». En este sentido, cfr. L. DE LUCA, Diritto ecclesiastico e sentimento religioso, en AA. Vv., Raccolta di scritti in onore di Arturo Carlo Femolo, I, Giuffre, Milano 1993, 404: «Ruffini ribadì, com'è noto, doversi il diritto ecclesiastico riguardare non tanto dal punto di vista dei rapporti fra lo Stato e la Chiesa quali entità di per sé e quasi astrattamente considerate, quanto da quello del diritto dei cittadini ad un assetto si tali rapporti che rispetti e garantisca, innanzi tutto, la sua libertà di fede».

${ }^{10}$ Sobre la evolución del enfoque del Derecho eclesiástico hacia la legislatio libertatis, cfr. J. OTADUY, «Derecho eclesiástico de Estado», en J. OTADUY - A. VIANA - J. SEDANo (eds.), Diccionario general de derecho canónico, III, Thomson Reuters Aranzadi, Cizur Menor (Navarra) 2013, 122-125 (en adelante, DGDC).

${ }^{11}$ Cfr. M. A. Herrera García., El objeto de la norma de Derecho eclesiástico, Anuario de Derecho eclesiástico del Estado 28 (2012) 756-768.
} 
mental en su tratado, es determinante a la hora de extraer conclusiones sobre la libertad religiosa. No sorprende que algunos autores lo consideren «più storico che giurista positivo» ${ }^{12}$. Como él mismo afirma, «persuasi come siamo che storia e dogma non possano sceverarsi in un sistema giuridico perfetto» ${ }^{13}$.

¿Qué dice Ruffini acerca de la libertad religiosa? Su pensamiento se puede sintetizar en tres aspectos concretos: la libertad religiosa como principio jurídico, como derecho de la persona y como base fundamental sobre la que deben fraguarse las relaciones entre la Iglesia y el Estado.

\subsection{La libertad religiosa como principio jurídico}

El término libertad religiosa admite diversos significados en el lenguaje común, por lo que Ruffini intenta en primer lugar determinar con la mayor exactitud posible cuál de todos es el más adecuado. Por una parte, están quienes desde un punto de vista filosófico la confunden con la libertad de pensamiento, donde el valor que se protege no es tanto la religión sino cualquier expresión del conocimiento humano. En este caso las manifestaciones sociales de carácter agnóstico o ateo acaban siendo sinónimo de las confesiones religio$\operatorname{sas}^{14}$. En cambio hay quienes desde un punto de vista teológico la reducen a la libertad eclesiástica, reclamando únicamente protección de la libertad de las iglesias institucionalmente constituidas ${ }^{15}$.

Ante la diversidad de sentidos él se decanta por considerarla desde una perspectiva jurídica, situándola en el terreno del Derecho: la libertad religiosa «non è, come il libero pensiero, un concetto o un principio filosofico, non

${ }^{12}$ A. Bertola, «Ruffini, F.», en Enciclopedia Católica..., cit., 1434.

13 F. RuffinI, La libertà religiosa come diritto pubblico subiettivo, Il Mulino, Bologna 1992, 65. Esta tendencia al historicismo como actitud intelectual, si bien tiene la ventaja de no desvincular las propuestas dogmáticas de la realidad histórica, presenta un inconveniente: al reducir la realidad humana a su dimensión histórica, en muchas ocasiones queda sin justificación adecuada la dimensión espiritual de la persona, provocándose una visión incompleta y poco profunda de la misma.

${ }^{14}$ Cfr. F. RufFInI, La libertà religiosa..., cit., 215: «Eretici, scismatici ed apostati, fattucchieri e negromanti, scettici, liberi pensatori ed esprits forts di ogni tempo e di ogni luogo sarebbero i suoi antesignani, i suoi campioni ed i suoi martiri:; illuminismo, deismo, razionalismo, volterianismo, naturalismo, materialismo, ecc. ecc. i suoi equivalenti».

15 Cfr. F. Ruffini, La libertà religiosa..., cit., 215: «Dovrebbe indicare la facoltà concessa, o meglio da concedersi ai seguaci di una determinata Chiesa di conformare gli atti della loro vita non solo privata, ma anche pubblica, in tutto e per tutto, ai precetti della loro credenza; così da avere lo Stato onninamente e supinamente soggetto alle proprie esigenze di carattere religioso». 
è neppure, come la libertà ecclesiastica, un concetto o un principio teologico; ma è un concetto o un principio essenzialmente e prettamente giuridico» ${ }^{16}$.

¿Por qué es un principio jurídico? Siguiendo el método histórico, se puede comprobar que desde los primeros siglos de la era cristiana la tradición política europea presentó al Estado y la religión como elementos estrechamente unidos. Con el tiempo, la práctica estatal llevó a los emperadores y monarcas a imponer una religión oficial -la que ellos personalmente profesaban-, generando una situación de desigualdad respecto a quienes adoptaban religiones distintas ${ }^{17}$. Frente a estos Estados de carácter confesional los ciudadanos reivindican la necesidad de libertad suficiente para desarrollar su respuesta ante la cuestión religiosa, reclamando que se garantice la ausencia de coacción exterior para desplegar su opción en la sociedad civil. Al poder estatal se le pide que tenga en cuenta todos los intereses morales de los ciudadanos, entre ellos el religioso, sin caer en actitudes discriminatorias: «deve lasciare il primo luogo a la spontanea e libera determinazione ed azione; guardandosi dal favorire alcuno di cotesti interessi, non solo a scapito, ma a semplice preferenza degli altri» ${ }^{18}$. Así pues, los datos de la historia enseñan que la libertad religiosa es un principio jurídico puesto que surge en el ámbito de las libertades políticas y civiles, no en el ámbito teológico ni filosófico.

Por ser un principio jurídico regulador de las relaciones entre el Estado y los ciudadanos, la libertad religiosa no debe tomar partido ni por la fe ni por la incredulidad. Afirma Ruffini que su fin es más modesto y práctico: consiste en crear, por parte del Estado, un régimen de inmunidad para que cada persona pueda llevar a cabo, con libertad, la búsqueda de la salvación eterna y de la verdad científica: «Il suo intento sta in creare e mantenere nella società un ordinamento giuridico tale che ogni individuo possa perseguire e conseguire a sua posta quei due fini supremi (la salvezza oltremondana e la vertità scientifica), senza che gli altri uomini, o separato o raggruppati in associazioni o Chiese, o anche

${ }^{16}$ F. RUFFinI, La libertà religiosa..., cit., 217.

17 Cfr. A. DE Fuenmayor, La libertad religiosa, Eunsa, Pamplona 1974, 115: «En un primer periodo que casi alcanza a la Revolución francesa, la confesionalidad del Estado -tanto en su versión católica como en las diversas versiones de la Reforma- va inseparablemente unida a la más absoluta intolerancia civil, pues el nuevo sistema acuñado en la fórmula cuius regio, eius religio sólo concede libertad a los príncipes en materia religiosa; y tanta que, con la de elegir la confesión, se arrogan -como inherente a la soberanía- la facultad de regular la profesión de fe por parte de los súbditos. Es el periodo del despotismo religioso de los Estados nacionales surgidos de las ruinas de la Cristiandad».

18 F. RuFFINI, La libertà religiosa..., cit., 75. 
impersonati in quella suprema collettività che è lo Stato, gli possano mettere in ciò il più piccolo impedimento $\mathrm{o}$ arrecare per ciò il più tenue danno» ${ }^{19}$. La libertad religiosa debe garantizar, por tanto, la ausencia de coacción exterior para que el ciudadano despliegue libremente su opción religiosa en la sociedad civil.

\subsection{La libertad religiosa como derecho de la persona}

Pero no basta con proclamar la libertad religiosa como principio jurídico; la propia historia enseña que las personas y los pueblos la reclaman como verdadero derecho, especialmente tras su reconocimiento en la Declaración de derechos de Virginia de 1776 y la Declaración francesa de los derechos del hombre y del ciudadano de 1789. Ante la realidad incontestable de su existencia Ruffini se pregunta qué tipo de derecho es la libertad religiosa.

Este derecho se encuadra dentro de los derechos de libertad del ciudadano. Debe tenerse en cuenta que el debate jurídico del siglo XIX viene marcado por la discusión doctrinal acerca de la naturaleza de los derechos de la persona, generando diversas tesis y corrientes ${ }^{20}$. Así, en el ámbito del Derecho francés, a partir de la doctrina del contrato social propuesta por Rosseau, la libertad del individuo es considerada como una realidad anterior y superior a la soberanía del Estado. La libertad de los ciudadanos es un derecho innato de los mismos ante el Estado, que sólo actúa como mero guardián de estas libertades. Desde esta perspectiva, cuanto más crece el poder estatal más disminuyen las libertades, produciéndose una radicalización de la concepción individualista de los derechos de la persona $^{21}$. En cambio, bajo la influencia de Hegel y Schelling, en el ámbito del Derecho germánico se acentúa la consideración del Estado como sujeto con derechos propios. En este sistema los derechos de los ciudadanos no son más que una concesión de la voluntad soberana estatal: la libertad sólo es un derecho reflejo reconocido por el Estado que decide autolimitarse en su poder ${ }^{22}$.

Ante la encrucijada derechos innatos-derechos reflejos Ruffini busca el equilibrio y retoma las tesis expuestas por Santi Romano, calificando los derechos

${ }^{19}$ F. RUfFini, La libertà religiosa..., cit., 217.

${ }^{20}$ Un estudio acerca de las diversas tesis y corrientes se recoge en: J. AGUDO GONZÁLEZ, Evolución y negación del derecho subjetivo, Revista digital de Derecho administrativo 5 (2011) 12-33, http:// revistas.uexternado.edu.co/index.php/Deradm/article/view/2952/2596.

${ }^{21}$ Cfr. F. Ruffint, La libertà religiosa..., cit., 219.

${ }^{22}$ Este argumento evolucionará en el ámbito del Derecho germánico hacia la consideración del Estado como titular de derechos públicos subjetivos: cfr. F. RUFFINI, La libertà religiosa..., cit., 225. 
de libertad -y consecuentemente la libertad religiosa- como verdaderos derechos subjetivos públicos ${ }^{23}$. Derecho subjetivo es todo interés -no sólo material o patrimonial, sino también moral- protegido por medio de un reconocimiento jurídico: «ogni potestà di volere, giuridicamente riconosciuta per la protezione di un interesse» ${ }^{24}$. No sólo el ciudadano goza de derechos sujetivos; también el Estado en cuanto dotado de personalidad jurídica, es titular de los mismos. De esta forma es posible establecer relaciones jurídicas entre los ciudadanos y el Estado, que llevan consigo derechos y obligaciones recíprocas: «di fatti, diritto subiettivo dello Stato è la sua potestà di impero; diritto subiettivo dell'individuo la sua libertà» ${ }^{25}$.

Los derechos subjetivos no son producto de la autolimitación del poder estatal. Frente a la propuesta germánica Ruffini adopta de Santi Romano la idea de un Estado que, en su mismo nacimiento, surge ya condicionado por su propio ordenamiento $^{26}$. Desde el principio el Estado de Derecho nace limitado, de forma necesaria y originaria, por los derechos de libertad de los ciudadanos. Estado, ordenamiento jurídico y derechos de libertad son realidades contemporáneas y para él no tiene sentido buscar qué es lo primero en el tiempo ${ }^{27}$. En conse-

${ }^{23}$ Cfr. F. Ruffini, La libertà religiosa..., cit., 237: «ond'è che già nella monografia del Romano sui Diritti pubblici subiettivi (1900) si incontrava la decisa affermazione che tali sono di qualificarsi anche i diritti di libertà (...) La qualità di diritti subiettivi (publici o privati) è stata asserita nella maniera più concreta e più esplicita quanto ai diritti di libertà. Né a questa, che può designarse come "communis opinio" presso di noi, hanno assentito i solli monografisti, ma i trattatisti più reputati e recenti, sia del Diritto costituzionale sia del Dirirtto amministrativo».

24 F. RUfFinI, La libertà religiosa..., cit., 242. En cuanto a la efectiva protección de la libertad religiosa, Ruffini advierte que ésta goza de un régimen de garantías judiciales ante eventuales violaciones cometidas por el poder ejecutivo o legislativo. Además, también viene protegida por unas serie de garantías políticas, que concreta en tres: la sanción expresa de la libertad religiosa en las Declaraciones de Derechos o Constituciones estatales, la opinión pública y el derecho de resistencia. Para una exposición más detallada de estas garantías judiciales y políticas: cfr. F. RUFFINI, La libertà religiosa..., cit., 249-261.

${ }^{25}$ F. RufFini, La libertà religiosa ..., cit., 241.

${ }^{26}$ Cfr. F. Ruffini, La libertà religiosa..., cit., 246. «Bisogna, prosegue il Romano, distinguere nella formazione dello Stato e del Diritto due momenti. Un momento iniziale, e cioè quello della stessa costituzione dello Stato, che è pure il momento della prima posizione del Diritto; poiché dato uno Stato, non si può non avere nel medesimo tempo un ordinamento giuridico (...). Soltanto in un secondo momento si ha la norma, manifestazione più tardiva e secondaria del diritto: la norma posta dallo Stato, organo supremo del diritto. Quindi, unicamente in questo secondo momento lo Stato può dirsi fonte del diritto».

27 Cfr. P. Calamandrei, Introduzione al libro de F. Ruffini, Diritti di libertá, La nuova Italia, Firenze ${ }^{2} 1946$, XII: «Il Ruffini sosteneva che nello Stato di Diritto, i diritti individuali e l'ordinamento giuridico sorgono ad un punto: sicché non ha senso ricercare quali di essi sia il prius e quale il posterius». 
cuencia, un Estado que niega los derechos de libertad de los ciudadanos se niega a sí mismo y a su propio ordenamiento ${ }^{28}$.

La libertad religiosa, además de un derecho subjetivo, es un derecho público, positivo y absoluto: «siamo così finalmente in grado di definire, dal punto di vista strettamentre giuridico, la libertà religiosa. Essa è un diritto subiettivo e non un semplice effetto riflesso o altro di somigliante; e per di più pubblico e non semplicemente privato. Soggiungiamo: diritto assoluto e positivo, e non semplicemente relativo e negativo» ${ }^{29}$.

Público, no privado, porque el ejercicio de esta libertad establece una relación jurídica entre el Estado y los ciudadanos y no simplemente entre particulares: de hecho, en la mayoría de Estados este derecho está proclamado solemnemente en las Constituciones y Declaraciones fundamentales y pertenece al ámbito del Derecho público. Absoluto porque goza de eficacia erga omnes y cualquier persona puede ejercerlo frente al Estado y frente a los demás ciudadanos. Y finalmente positivo en el sentido de que requiere una amplia producción legislativa que regule las diversas manifestaciones individuales y colectivas que conlleva su ejercicio ${ }^{30}$.

Una vez definida la libertad religiosa como derecho subjetivo público, positivo y absoluto, Ruffini se detiene a considerar cuál es el objeto de este derecho. Puesto que el ciudadano es libre de creer o no, su protección debe abarcar tanto la respuesta positiva ante el fenómeno religioso como la negativa. Al margen de los términos con que la ley estatal designe esta libertad (libertad de religión, de confesión, de creencia, de fe...), lo importante es que la legislación custodie tanto la profesión de una fe concreta o un determinado credo religioso como la ausencia de profesión de fe. «La libertà religiosa è la facoltà di credere a quello che più gli place, o di non credere, si più gli place, a nulla. Onde ugualmente riconosciuto e protetto deve essere il diritto alla irreligione, all'aconfessionismo, alla miscredenza, alla incredulità. Diceva con tutta ragione il D'Alambert: l'incredulité est une espèce de foi pour la plupart des impies» ${ }^{31}$. Por

${ }^{28}$ Cfr. F. RufFInI, La libertà religiosa..., cit., 248: «Quella dello Stato è, per rispetto ai diritti di libertà dei cittadini, non una limitazione volontaria ed acquisita, sì bene una limitazione necessaria e congenita. Di qui l'intangibilità e l'imprescrittibilità di quei diritti». El Estado no puede destruir el derecho y el orden jurídico sin destruirse a sí mismo.

29 F. RUFFini, La libertà religiosa..., cit., 277.

${ }^{30}$ Cfr. F. Ruffini, La libertà religiosa..., cit., 273-276.

${ }^{31}$ F. RUFFINI, La libertà religiosa..., cit., 279. 
tanto, el objeto de este derecho debe comprender tanto la respuesta positiva como negativa del ciudadano ante la cuestión religiosa.

Por último, Ruffini advierte que la libertad religiosa abarca una doble vertiente en cuanto que su ejercicio puede realizarse de forma individual (libertad de conciencia) o colectiva (libertad de culto). Ambas dimensiones son inseparables para que exista un adecuado ejercicio de este derecho. La libertad de conciencia es la libre respuesta a la opción religiosa que personalmente realiza cada ciudadano, mientras que la libertad de culto hace referencia a su libre ejercicio como fenómeno social ${ }^{32}$. Para garantizar realmente la libertad religiosa de los ciudadanos, el Estado debe adoptar una serie de medidas que protejan ambas libertades. Las principales medidas protectoras de la libertad de conciencia que Ruffini propone son tres:

a) Medidas negativas consistentes en eliminar cualquier tipo de discriminación, castigo o inhabilitación por motivos religiosos. En la legislación italiana del momento estas medidas se garantizan fundamentalmente, en el ámbito del Derecho civil, con la Ley Sineo del 19 de junio de 1848, al declarar el principio de igualdad jurídica de los ciudadanos sin hacer distinciones por motivos religiosos ${ }^{33}$. En el ámbito penal, el Código de 1889 se abstiene de castigar la herejía, la apostasía, el cisma y el proselitismo de cultos no oficiales.

b) Medidas indirectas dirigidas a facilitar que las relaciones entre el Estado y los ciudadanos transcurran sin intromisión en su libertad religiosa. Para llevar a cabo este programa, Ruffini defiende la necesidad de los Registros oficiales para la inscripción del estado civil de los ciudadanos, la aconfesionalidad de la enseñanza pública, la institución del matrimonio civil, la transformación del juramento político y judicial, la secularización de la asistencia pública y la creación de cementerios comunes ${ }^{34}$.

${ }^{32}$ Cfr. F. Ruffini, La libertà religiosa..., cit., 278-279.

33 El 19 de junio de 1848 se aprueba la ley Sineo compuesta de un solo artículo: «La differenza di culto non forma eccezione al godimento dei diritti civili e politici ed all'ammessibilità alle cariche civili e militare». Esta ley, al afirmar el principio de igualdad jurídica de los ciudadanos sin distinción por motivos religiosos, implica el abandono de la confesionalidad civil. Téngase en cuenta que ésta será la única ley que conocerá Francesco Ruffini en materia de libertad religiosa; no sorprende entonces que la califique como «il testo fondamentale, e quasi la Magna Carta della nostra libertá religiosa»: cfr. F. RUFFINI, Corso di diritto eclesiastico..., cit., 131.

34 Para un análisis más detallado de estas medidas, cfr. F. RUFFINI, La libertà religiosa..., cit., 282288. Estas medidas tienen como objeto convertir el Estado confesional en aconfesional, lo que no significa que sea anticonfesional. 
c) Medidas directas y positivas, fundamentalmente la sanción del derecho de libertad religiosa en las Declaraciones de derechos y en las Constituciones estatales ${ }^{35}$.

En cuanto a la libertad de culto, sostiene que la legislación estatal debe proteger tanto las manifestaciones positivas propias del ejercicio de una religión concreta como las negativas derivadas de la incredulidad o el ateísmo. En este sentido, no duda en recriminar al legislador italiano «la assoluta mancanza di ogni tutela specifica di quelle cerimonie e di quei riti, in cui si concretano la manifestazione e l'esercizio, non solo delle credenze positive, ma anche delle negative. Si pensi alle sepolture civili, oggetto della più veemente esecrazione dei credenti; alla cremazione, condannata fieramente della Chiesa; alle varie società del libero pensiero e ai relativi congressi; e magari ai riti, ridicoli fin che si vuole, ma per ciò non meno rispettabili delle loggie massoniche. Queste forme di esercizio della libertà religiosa non trovano altra tutela che nel diritto comune, il che costituisce una disparità di trattamento non indiferente e non giustificabile, in confronto del'esercizio delle altre forme della libertà religiosa. Esse non sono in vero meno soggette che le credenze positive, agli attentati degli intolleranti e dei fanatici» ${ }^{36}$.

\subsection{La libertad religiosa en el sistema de relaciones Iglesia-Estado}

Por último Ruffini hace también referencia al papel que la libertad religiosa juega en el sistema de relaciones Iglesia-Estado. Como se ha visto anteriormente, la relación entre la Iglesia católica y el Estado italiano es una de las principales preocupaciones de los primeros eclesiasticistas. Tras el proceso unificador del Reino de Italia se consolida en la península un Estado laico que «proclamava la sua incompetenza in materia religiosa ma tale incompetenza si traduceva, al meno concettualmente, in neutralità che si estendeva a tutte le opinioni (...), e si afferma lo Stato agnostico non solo verso ciascuna istituzione ecclesiastica, ma verso lo stesso fattore religioso» ${ }^{37}$. En este Estado laico los

${ }^{35}$ Ruffini lamenta la falta de una disposición en este sentido en el Estatuto de 1848. No hay que olvidar que será en la Constitución de 1948 cuando el Estado italiano consagre el derecho de libertad religiosa.

${ }^{36}$ F. RuffinI, La libertà religiosa..., cit., 291. Téngase en cuenta que, en este punto, Ruffini se refiere a las condenas que el magisterio de la Iglesia del XIX y principios del XX hace de estas sociedades: magisterio que, dada su formación y espíritu liberal, no comparte.

37 C. CARDIA, «Stato laico», en Aa. Vv. - F. CAlasso, Enciclopedia del Diritto, XLIII, Giuffrè, Milano $1990,879$. 
eclesiasticistas se plantean cuál debe ser el tratamiento jurídico de la Iglesia católica y de las demás confesiones religiosas. Francesco Scaduto defiende que, como consecuencia de la neutralidad, a la Iglesia católica y a todas las demás iglesias se les debe aplicar el derecho común como se hace con otras instituciones de derecho público, negando cualquier diferencia o especificidad ${ }^{38}$. Así como todas las personas físicas son iguales ante la ley, también lo deben ser las personas morales: si se reconoce a la Iglesia católica un status diferente cabe el peligro de privilegiarla frente a las demás instituciones.

En cambio, sin dejar de afirmar la soberanía del Estado para determinar la posición de las iglesias en su ordenamiento jurídico, Ruffini sostiene que la reducción al derecho común de las mismas puede resultar un atentado contra la justicia, sobre todo si el poder estatal actúa sin considerar la realidad histórica, social y espiritual de su pueblo. Por esta razón el Estado italiano debe atender a la existencia de la Iglesia católica en el país, su gran difusión entre los ciudadanos y su considerable organización. Estos factores impiden considerarla como una confesión más, y no se puede pretender regularla según las normas de derecho común: «parlare di uguaglianza o anche solo di equivalenza è semplicemente ridicolo per rispetto a quei paesi del Continente europeo -la nostra Italia ad esempio- in cui tutte le confessioni acattoliche non riescono a porre in campo se non poche migliaia di addetti, e ancora fra loro disgregati e dispersi, di contro ai compatti milioni di seguaci della Chiesa cattolica. In tale condizione di cose, il volere attuare una perfetta parità o uguaglianza di trattamento giuridico verrebbe necessariamente a significare che lo Stato dovrebbe, in omaggio a pure astrazioni o teorie, disconoscere la concreta realtà dei fatti; il che allo Stato non è concesso, dato che la sua vita e la sua azione si svolgono esclusivamente nel mondo delle realtà ${ }^{39}$. La aplicación de una igualdad absoluta y abstracta puede llevar a tratar de modo igual relaciones jurídicas desiguales, vulnerando el principio de justicia que consiste no en dar a todos lo mismo, sino a cada uno lo suyo: «vi é una parità nel senso fal-

${ }^{38}$ Cfr. F. SCADUTO, Stato e confessioni religiose, Roma 1911, 14: «Lo Stato moderno, mentre da una parte non considera più la Chiesa cattolica come comunione privilegiata, dall'altra, però, non si permette più, diversamente che lo Stato assolutista, sebbene illuminato del secolo XVIII, di ingerirsi nel governo, meramente spirituale, della Chiesa (...). Lo Stato moderno, dunque, pur esercitando un diritto di tutela e vigilanza sulla Chiesa, lo esercita negli stessi limiti che per gli altri enti esistenti dentro il suo territorio, applicando perciò il diritto comune relativo agli enti di diritto pubblico».

39 F. RufFinI, La libertà religiosa..., cit., 502. 
so, che è quella dell'uguaglianza assoluta, astratta, matematica, ed è una parità nel senso giusto, chè è quella dell'uguaglianza relativa, concreta, giuridica; poiché, come scrisse giustamente il Kalh, il vero principio di parità non suona: a ciascuno lo stesso, ma a ciascuno il suo» ${ }^{40}$.

Aunque se otorgue a la Iglesia católica un tratamiento especial atendiendo a su realidad específica, Ruffini defiende que esta singularidad no tiene por qué implicar una vulneración de la libertad religiosa de los ciudadanos. Lo importante es que el Estado garantice a todos sus ciudadanos el libre ejercicio de su derecho, tanto en su aspecto positivo como negativo, individual como colectivo. Y garantizar este derecho es posible no sólo en regímenes estatales separatistas sino también confesionales, aunque el Estado regule diversamente las confesiones religiosas que presentan amplias diferencias numéricas e históricas.

\section{Aspectos COINCIDENTES DE LA PROPUESTA DE RUfFINI Y LA DECLARACIÓN CONCILIAR DIGNITATIS HUMANAE}

Treinta años después del fallecimiento de Ruffini, Pablo VI aprueba la Declaración conciliar Dignitatis humanae sobre la libertad religiosa con fecha de 7 de diciembre de 1965. Del texto de este documento se desprenden algunos de los principales aspectos magisteriales acerca de esta libertad:

a) En primer lugar, el Vaticano II determina con gran precisión la naturaleza jurídico-civil de la libertad religiosa, al afirmar que esta libertad consiste en el deber que tiene el Estado -como cualquier otra potestad humana- de garantizar un régimen de inmunidad de coacción para que los sujetos de este derecho puedan ejercer la opción sin trabas ni condicionamientos ${ }^{41}$.

${ }^{40}$ F. Ruffins, La libertà religiosa..., cit., 502. Como señala Mantecón: «El problema señalado por Ruffini lleva a identificar en el principio de igualdad un corolario necesario, especialmente útil a la hora de tratar el problema religioso en su vertiente asociativa e institucional, cual es el principio de no discriminación por razones religiosas. En efecto, si cualquier persona puede disfrutar del derecho de libertad religiosa en razón a su radical igualdad y dignidad en cuanto a su naturaleza, no puede decirse lo mismo de manera absoluta de las distintas iglesias o entes de naturaleza religiosa»: cfr. J. MANTECÓN SANCHO, El derecho fundamental de libertad religiosa, Eunsa, Pamplona 1996, 72.

${ }^{41}$ Cfr. Dec. Dignitatis humanae, 2: «La persona humana tiene derecho a la libertad religiosa. Esta libertad consiste en que todos los hombres han de estar inmunes de coacción, tanto por parte de individuos como de grupos sociales y de cualquier potestad humana, y esto de tal manera que, en materia religiosa, ni se obligue a nadie a obrar contra su conciencia, ni se le impida que actúe conforme a ella en privado y en público, sólo o asociado con otros, dentro de los límites debidos». 
b) Esta libertad debe ser reconocida en el ordenamiento jurídico, de manera que llegue a convertirse en un verdadero derecho civil ${ }^{42}$.

c) El objeto de este derecho abarca tanto las expresiones positivas como negativas de la opción religiosa ${ }^{43}$.

d) Sujeto de este derecho es tanto la persona singular como también los grupos sociales ${ }^{44}$.

e) El régimen de libertad religiosa es compatible con un régimen estatal que otorgue a una determinada iglesia un especial reconocimiento civil. Este reconocimiento no vulnera la justicia si se respeta la libertad religiosa de los demás ciudadanos y confesiones ${ }^{45}$.

f) El Estado debe garantizar que no se aplicará ninguna discriminación entre sus ciudadanos por motivos religiosos ${ }^{46}$.

A la vista de estas tesis magisteriales, fácilmente se observa la coincidencia de las mismas con las propuestas por Ruffini acerca de la naturaleza y el alcance de la libertad religiosa: cada uno de estos puntos fueron ya señalados por el profesor italiano tres décadas antes. Se descubre así una continuidad en la construcción dogmática del régimen jurídico de esta libertad; continuidad que se ha ido afianzando en el ámbito de la ciencia jurídica ${ }^{47}$.

${ }^{42}$ Cfr. Dec. Dignitatis humanae, 2: «Este derecho de la persona humana a la libertad religiosa ha de ser reconocido en el ordenamiento jurídico de la sociedad, de tal manera que llegue a convertirse en un derecho civil».

${ }^{43}$ Cfr. Dec. Dignitatis humanae, 2: «El derecho a esta inmunidad permanece también en aquellos que no cumplen la obligación de buscar la verdad y de adherirse a ella, y su ejercicio, con tal de que se guarde el justo orden público, no puede ser impedido».

${ }^{44}$ Cfr. Dec. Dignitatis humanae, 3: «El ejercicio de la religión, por su propia índole, consiste, sobre todo, en los actos internos voluntarios y libres, por los que el hombre se relaciona directamente a Dios: actos de este género no pueden ser mandados ni prohibidos por una potestad meramente humana. Y la misma naturaleza social del hombre exige que éste manifieste externamente los actos internos de religión, que se comunique con otros en materia religiosa, que profese su religión de forma comunitaria».

45 Cfr. Dec. Dignitatis humanae, 6: «Si, consideradas las circunstancias peculiares de los pueblos, se da a una comunidad religiosa un especial reconocimiento civil en la ordenación jurídica de la sociedad, es necesario que a la vez se reconozca y respete el derecho a la libertad en materia religiosa a todos los ciudadanos y comunidades religiosas».

46 Cfr. Dec. Dignitatis humanae, 6: «la autoridad civil debe proveer a que la igualdad jurídica de los ciudadanos, que pertenece también al bien común de la sociedad, jamás, ni abierta ni ocultamente, sea lesionada por motivos religiosos, y a que no se haga discriminación entre ellos».

47 Por ejemplo, esta continuidad en el tratamiento jurídico puede observarse en la Ley Orgánica de Libertad religiosa 7/1980, art. 2,1: «La libertad religiosa y de culto garantizada por la Constitución comprende, con la consiguiente inmunidad de coacción, el derecho de toda persona a: 
Puesto que hay una coincidencia en lo referente a la regulación jurídica de la libertad religiosa, cabe preguntarse si existe alguna diferencia entre ambas enseñanzas. Tras una lectura detallada de la obra de Ruffini y del magisterio conciliar, se puede afirmar que la diferencia se encuentra, principalmente, en la fundamentación del derecho.

No se debe olvidar que Ruffini desarrolla su pensamiento según los esquemas liberales propios del siglo XIX y que su amplio espíritu de tolerancia acaba identificándose con el escepticismo frente a la verdad ${ }^{48}$. Así observa que la convicción de poseer la verdad en materia religiosa provoca en las personas un celo proselitista que les lleva a buscar la conversión de quienes se encuentran en el error. Este celo no presenta problemas mientras se utilicen armas puramente espirituales, incluso es justificable. Pero los hechos históricos enseñan que es muy fácil pasar de lo que él denomina intransigencia teológica -el convencimiento de poseer la verdadera religión- a la intransigencia civil, y de-

a) Profesar las creencias religiosas que libremente elija o no profesar ninguna; cambiar de confesión o abandonar la que tenía, manifestar libremente sus propias creencias religiosas o la ausencia de las mismas, o abstenerse de declarar sobre ellas.

b) Practicar los actos de culto y recibir asistencia religiosa de su propia confesión; conmemorar sus festividades; celebrar sus ritos matrimoniales; recibir sepultura digna, sin discriminación por motivos religiosos, y no ser obligado a practicar actos de culto o a recibir asistencia religiosa contraria a sus convicciones personales.

c) Recibir e impartir enseñanza e información religiosa de toda índole, ya sea oralmente, por escrito o por cualquier otro procedimiento; elegir para sí, y para los menores no emancipados e incapacitados, bajo su dependencia, dentro y fuera del ámbito escolar, la educación religiosa y moral que esté de acuerdo con sus propias convicciones.

d) Reunirse o manifestarse públicamente con fines religiosos y asociarse para desarrollar comunitariamente sus actividades religiosas de conformidad con el ordenamiento jurídico general y lo establecido en la presente Ley Orgánica».

${ }^{48}$ Como él mismo sostiene, «riesce più facile di innamorarsi della tolleranza e mantenervisi fedele per sempre a uno spirito filosofico e scettico di fronte al problema della verità assoluta, che non a uno spirito teologico e credente nel dogma della verità rivelata»: cfr. F. RUFFINI, La libertà religiosa..., cit., 495. Partiendo de este espíritu relativista se comprende que Ruffini no llegue a entender la condena que el magisterio eclesiástico del momento hizo de las libertades. La condena de la libertad de conciencia y de culto de los Pontífices del siglo XIX provocó la protesta de los espíritus liberales, por cuanto la Iglesia les parecía contraria a las libertades humanas y que permanecía anclada en los principios estatales del Antiguo Régimen. No tenían en cuenta que, con esta condena, la Iglesia no censuraba la libertad humana en sí misma sino la pretensión de una libertad absoluta, sin responsabilidad ante el Creador y autónoma de toda norma moral. En cuanto al rechazo pontificio de la libertad de culto, no hay que olvidar que bajo el nombre de esta libertad se aplicaba en los Estados una legislación laicista, que llevó en muchos casos a despojar a la Iglesia de sus libertades y sus bienes. Para una adecuada comprensión de la condena magisterial de estas libertades civiles puede consultarse: cfr. G. DEL PoZO ABEjón, La Iglesia y la libertad religiosa, BAC, Madrid 2007, 99-139. 
nuncia esta transición como uno de los eventos más tremendos en la historia de la humanidad: «cotesto trasformarsi o, se si vuole, snaturarsi della intolleranza ecclesiastica (sentimento pienamente giustificabile e rispettabile) in intolleranza civile (...), fu uno degli eventi più imponenti e più tremendi nella storia dell'umanità. Il trapasso era fatale» ${ }^{49}$.

Como consecuencia opta por desvincular religión y verdad, puesto que esta vinculación es peligrosa. Opina que es más sólido, para la construcción de un verdadero régimen de libertad, entender la religión como un fenómeno subjetivo, producto del consenso y la indiferencia, donde nadie se arrogue derechos en nombre de la verdad. La religión así concebida tiene un carácter más superficial, pero a Ruffini le parece más segura a la hora de construir un régimen de libertad civil ${ }^{50}$. Con este razonamiento se permite extraer conclusiones teológico-morales de premisas que pertenecen al ámbito civil, sin llegar a distinguir que autonomía jurídica y autonomía moral son dos planos diversos que deben diferenciarse claramente para no caer en confusión ${ }^{51}$. Al desvincularse de la verdad, la religión corre el riesgo de convertirse en un fenómeno subjetivo sin más fundamento que la propia voluntad humana.

En cambio, en este punto la declaración Dignitatis bumanae proclama que la libertad religiosa debe ser reconocida precisamente para garantizar la

49 F. RuFfini, La libertà religiosa..., cit., 87-88. Es frecuente, en los autores liberales, identificar la intransigencia teológica con la intransigencia civil, confundiendo el orden teológico y político, sin respetar la autonomía específica de cada uno de ellos. Como señala Giacchi, «lungi dall'avere una origine anticristiana, la libertà religiosa è nata, all'opposto, soltanto con el cristianesimo». Los Apóstoles, al exigir frente al poder público la libertad necesaria para obedecer a Dios antes que a los hombres, fueron los primeros en reclamar este derecho. La libertad religiosa aparece en la historia cuando, por vez primera, se proclama la existencia de dos órdenes distintos: el político-civil y el espiritual. Cfr. O. GIACCHI, Il significato storico di Montalembert, en Libertà Della Chiesa e autorità dello Stato, Giuffrè, Milano 1963, 141-143.

${ }^{50}$ Cfr. F. Ruffint, La libertà religiosa..., cit., 161: «Ne consegue che il fondamento filosofico-scettico della libertà religiosa si chiarisca di già molto meno profondo, se si vuole, ma incomparabilmente più solido, che non il teologico-mistico. Ed è questo un rilievo della massima importanza, che dovremo tener presente in tutta la nostra restante trattazione».

${ }^{51}$ Cfr. A. DE Fuenmayor, La libertad religiosa..., cit., 29: «Conviene advertir que la libertad religiosa es ciertamente un derecho de la persona -y en esto se identifica con los restantes derechos fundamentales del hombre, pues corresponde a toda la persona con independencia de sus disposiciones subjetivas-, pero tiene como nota distintiva última el hacer referencia a la relación del hombre con Dios, y no solamente a la relación con los demás hombres y con la sociedad civil. Por eso es de capital importancia situar la libertad religiosa exactamente en el plano donde la ha situado el Concilio -que es el plano civil- y evitar que la noción de libertad religiosa se desplace al plano moral, porque este deslizamiento daría origen a graves confusiones». 
obligación moral que toda persona tiene de buscar la verdad en materia religiosa: no hay, en el planteamiento conciliar, una renuncia a la verdad. Si bien es cierto que a lo largo de la historia se han llevado a cabo actuaciones que vulneran este derecho en nombre de la verdadera religión ${ }^{52}$, este argumento no autoriza para dejar de reconocer que la verdadera religión sólo puede ser una y, por este motivo, toda persona tiene el deber moral de buscarla ${ }^{53}$. Ahora bien, en esta búsqueda nadie debe ser constreñido por la fuerza, aunque se equivoque, ya que esta búsqueda sólo puede realizarse libremente de acuerdo con la dignidad propia de la persona ${ }^{54}$. Verdad y libertad son dos aspectos inseparables; es más, reconocer la existencia de la verdad es la garantía de la especificidad de este derecho. Cuando se renuncia a la verdad cabe el peligro de que la religión termine siendo considerada como un mero fenómeno subjetivo equiparable a cualquier ideología: si la libertad religiosa pierde su objeto específico puede acabar subsumida por la libertad de pensamiento y de asociación.

\section{CONCLUSión}

Con gran acierto Ruffini distingue en la libertad religiosa tres aspectos fundamentales. En cuanto principio jurídico esta libertad reclama un ámbito de autonomía ante el poder estatal para que el ciudadano pueda desplegar su opción religiosa de forma individual y colectiva. En cuanto derecho de la persona, debe ser reconocido y protegido como derecho público subjetivo para su plena eficacia en el ordenamiento jurídico. Y en tercer lugar, el respeto a la libertad religiosa debe ser el fundamento de toda relación jurídica entre el Estado y las distintas confesiones, aún en el caso de Estados confesionales. Hay

${ }^{52}$ Cfr. Dec. Dignitatis humanae, 12: «Aunque en la vida del Pueblo de Dios, peregrinó a través de las vicisitudes de la historia humana, se ha dado a veces un comportamiento menos conforme con el espíritu evangélico, e incluso contrario a él, no obstante, siempre se mantuvo la doctrina de la Iglesia de que nadie sea forzado a abrazar la fe».

53 Cfr. Dec. Dignitatis humanae, 1: «Todos los hombres están obligados a buscar la verdad, sobre todo en lo que se refiere a Dios y a su Iglesia, y, una vez conocida, a abrazarla y practicarla».

${ }^{54}$ Cfr. Dec. Dignitatis humanae, 2: «El derecho a la libertad religiosa no se funda en la disposición subjetiva de la persona. Por lo cual, el derecho a esta inmunidad permanece también en aquellos que no cumplen la obligación de buscar la verdad y de adherirse a ella». Con la declaración conciliar se consolida un cambio de orientación respecto a las enseñanzas magisteriales precedentes, puesto que el núcleo del discurso no es tanto la primacía de la Verdad sino la de la dignidad humana: cfr. J. MANTECÓN SANCHO, «Libertad religiosa», DGDC, V, 165-166. 
que destacar que estos aspectos coinciden con los propuestos años más tarde en la Declaración conciliar Dignitatis bumanae.

Ahora bien, la historia demuestra que el convencimiento de poseer la verdad en materia religiosa fácilmente culmina en un régimen de intransigencia civil. Puesto que verdad y libertad son difícilmente conciliables en la práctica, Ruffini concluye que es preferible optar por un concepto de religión fundamentado en el escepticismo intelectual y en el relativismo, sin llegar a distinguir adecuadamente entre autonomía jurídica y moral.

Cuando verdad y libertad no se concilian adecuadamente cabe advertir la existencia de dos riesgos posibles. Por un lado, como certeramente advierte Ruffini, el peligro de aquellos que en nombre de la verdad religiosa atropellan y violan el justo ámbito de libertad propio de toda persona en esta materia. En este caso, la afirmación de la verdad puede llevar a la negación de la libertad, suponiendo una terrible violación de la dignidad humana. Pero también cabe el riesgo, como le ocurre al maestro italiano, de caer en el extremo contrario al negar la verdad para afirmar la libertad. Este peligro, menos violento en sus manifestaciones, no por eso deja de ser pernicioso: «Después de la caída en muchos países de las ideologías que condicionaban la política a una concepción totalitaria del mundo -la primera entre ellas el marxismo- existe hoy un riesgo no menos grave debido a la negación de los derechos fundamentales de la persona humana y la absorción en la política de la misma inquietud religiosa que habita en el corazón de todo ser humano: es el riesgo de la alianza entre democracia y relativismo ético, que quita a la convivencia civil cualquier punto de referencia moral, despojándola más radicalmente del reconocimiento de la verdad» ${ }^{55}$.

Un régimen estatal con fundamentos relativistas, donde se niega la capacidad humana de conocer la verdad, fácilmente deviene en un mero sistema instrumental y utilitarista al servicio de los intereses del más fuerte: «sin una base moral objetiva, ni siquiera la democracia puede asegurar la paz estable, tanto más que la paz no fundamentada sobre los valores de la dignidad humana y de la solidaridad entre todos los hombres es a menudo ilusoria. En efecto, en los mismos regímenes participativos la regulación de los intereses se produce con frecuencia en beneficio de los más fuertes, que tienen mayor capacidad para maniobrar no sólo las palancas de poder, sino incluso la forma-

55 Enc. Veritatis splendor, 101. 
ción del consenso. En una situación así, la democracia se convierte fácilmente en una palabra vacía» ${ }^{56}$.

En nuestros días persiste el temor de que el convencimiento de poseer la verdad en materia religiosa sea incompatible con un sistema de libertad religiosa. Por el contrario debería tenerse en cuenta que un planteamiento relativista que reduce la religión al ámbito de la mera subjetividad puede suponer, a la larga, la desprotección del propio derecho de libertad religiosa al perder éste su objeto específico. Así pues, fundamentar adecuadamente este derecho no es una cuestión baladí. Si bien la opción de Ruffini de renunciar a la verdad sigue latiendo en el pensamiento político actual, la doctrina magisterial continúa iluminando el camino para una efectiva protección del derecho de libertad religiosa.

\footnotetext{
${ }^{56}$ Enc. Evangelium vitae, 70.
} 


\section{Bibliografía}

Agudo GonzáLez, J., Evolución y negación del derecho subjetivo, Revista digital de Derecho administrativo 5 (2011) en http://revistas.uexternado.edu.co/ index.php/Deradm.

Bertola, A., «Ruffini, F.», Enciclopedia Cattolica, Firenze 1952.

Calamandrei, P., Introduzione al libro de F. Ruffini, Diritti di libertá, La nuova Italia, Firenze ${ }^{2} 1946$.

Cardia, C., «Stato laico», en Aa. Vv. - F. Calasso, Enciclopedia del Diritto, XLIII, Giuffrè, Milano 1990.

Colombo, A., «Ruffini, F.», en AA. Vv. - P. Fedele, Grande Dizionario Enciclopedico UTET, XVII, Torino ${ }^{4} 1990$.

De Fuenmayor, A., Derecho eclesiástico del Estado español, Comares, Granada 2007.

—, La libertad religiosa, Eunsa, Pamplona 1974.

De la Hera, A., La ciencia del Derecho eclesiástico en Italia. Notas para su recepción en España, El fenómeno religioso en España, Instituto de Estudios políticos, Madrid 1972.

Del Pozo Abejón, G., La Iglesia y la libertad religiosa, BAC, Madrid 2007.

De LucA, L., Diritto ecclesiastico e sentimento religioso, en AA. Vv., Raccolta di scritti in onore di Arturo Carlo femolo, I, Giuffrè, Milano 1963, 392-412.

FERRARI, S., Ideologia e dogmatica nel diritto ecclesiastico italiano. Manuali e riviste (1929-1979), Giuffrè, Milano 1979.

GIACCHI, O., Il significato storico di Montalembert, Libertà Della Chiesa e autorità dello Stato, Giuffrè, Milano 1963.

Herrera García, M. A., El objeto de la norma de Derecho eclesiástico, Anuario de Derecho eclesiástico del Estado 28 (2012) 739-784.

Ibán, I. C., En los orígenes del Derecho eclesiástico, Boletín Oficial del Estado, Madrid 2004.

Jemolo, A. C., «Ruffini, F.», en A. AZara - E. Eula (dirs.), Novissimo Digesto Italiano, XVI, Torino 1982.

JuAn Pablo II, Encíclica Evangelium vitae (25 de marzo de 1995).

—, Encíclica Veritatis splendor (6 de agosto de 1993).

LaricCiA, S., «Stato e Chiesa (rapporti tra)», en AA. Vv. - F. CALASso, Enciclopedia del Diritto, Giuffrè, Milano 1990, XLIII.

Lombardía, P., Derecho eclesiástico del Estado español, Eunsa, Pamplona 1980. 
Mantecón SAncho, J., El derecho fundamental de libertad religiosa, Eunsa, Pamplona 1996.

Otaduy, J. - Viana, A. - Sedano, J. (eds.), Diccionario general de derecho canónico, Thomson Reuters Aranzadi, Cizur Menor (Navarra) 2013.

Pío IX, Encíclica Ubi nos (15 de mayo de 1887²).

Redondo, G., La Iglesia en el mundo contemporáneo, II, Eunsa, Pamplona 1979.

RufFInI, F., Diritti di libertá, La nuova Italia, Firenze ${ }^{2} 1946$.

—, Corso di Diritto ecclesiastico italiano. La libertà religiosa come diritto pubblico subiettivo, F. Bocca, Torino 1924.

—, La libertà religiosa come diritto pubblico subiettivo, Il Mulino, Bologna 1992.

—, La libertà religiosa. Storia dell'idea, Feltrinelli, Torino 1901.

SCADUTO, F., Stato e confessioni religiose, Roma 1911.

Tozzí, V., 150 anni di unità dell'Italia. Breve storia e problema attualli della libertà religiosa, Anuario de Derecho eclesiástico del Estado 28 (2012) 675-722.

VATICANO II, Declaración conciliar Dignitatis humanae (7 de diciembre de 1965). 